\title{
Identification of a General Odorant Receptor for Repellents in the Asian Corn Borer Ostrinia furnacalis
}

\author{
Jie Yu', Bin Yang ${ }^{1 *}$, Yajun Chang ${ }^{1,2}$, Yu Zhang ${ }^{1,3}$ and Guirong Wang ${ }^{1,4 *}$ \\ 1 State Key Laboratory for Biology of Plant Diseases and Insect Pests, Institute of Plant Protection, Chinese Academy \\ of Agricultural Sciences, Beijing, China, ${ }^{2}$ College of Plant Protection, Henan Agricultural University, Zhengzhou, China, \\ ${ }^{3}$ Research Center for Grassland Entomology, Inner Mongolia Agricultural University, Hohhot, China, ${ }^{4}$ Lingnan Guangdong \\ Laboratory of Modern Agriculture, Genome Analysis Laboratory of the Ministry of Agriculture, Agricultural Genomics Institute \\ at Shenzhen, Chinese Academy of Agricultural Sciences, Shenzhen, China
}

\section{OPEN ACCESS}

Edited by:

Philippe Lucas,

Institut National de la Recherche Agronomique, France

Reviewed by:

Ya-Nan Zhang,

Huaibei Normal University, China Hao Guo,

Chinese Academy of Sciences, China

*Correspondence: Bin Yang

byang@ippcaas.cn Guirong Wang wangguirong@caas.cn

Specialty section: This article was submitted to Invertebrate Physiology, a section of the journal

Frontiers in Physiology

Received: 26 November 2019 Accepted: 17 February 2020

Published: 13 March 2020

Citation:

Yu J, Yang B, Chang Y, Zhang Y and Wang G (2020) Identification of a General Odorant Receptor for Repellents in the Asian Corn Borer

Ostrinia furnacalis.

Front. Physiol. 11:176. doi: 10.3389/fphys.2020.00176
Attractants and repellents are considered to be an environment-friendly approach for pest management. Odorant receptors (ORs), which are located on the dendritic membranes of olfactory sensory neurons in insects, are essential genes for recognizing attractants and repellents. In the Asian corn borer, Ostrinia furnacalis, ORs that respond to sex pheromones have been characterized, but general ORs for plant odorants, especially for repellents, have not been identified. Nonanal is a plant volatile of maize that could result in avoidance of the oviposition process for female adults in $O$. furnacalis. In this study, we identified a female-biased OR that responds to nonanal using a Xenopus oocyte expression system. In addition, we found that OfurOR27 was also sensitive to two other compounds, octanal and 1-octanol. Behavioral analysis showed that octanal and 1-octanol also caused female avoidance of oviposition. Our results indicated that OfurOR27 is an OR that is sensitive to repellents. Moreover, the two newly identified repellents may help to develop a chemical ecology approach for pest control in O. furnacalis.

Keywords: odorant receptor, heterologous expression system, host plant volatile, repellent, nonanal

\section{INTRODUCTION}

Chemical ecology is now established as an approach for pest management. Pheromones have been identified in many insects and are great attractants to interfere with mating behaviors by trapping large numbers of male adults (Witzgall et al., 2010). However, pheromones only attract males, which is a major limitation, because females lay eggs and the mating rate might not be affected if the males can mate many times, as in some species. In this case, plant volatiles are considered to have great application prospects since they were effective for trapping both males and females (Gregg et al., 2010). Some plant volatiles have been identified as involved in oviposition, although the perception mechanism for those plant volatiles was still unknown (Mitchell et al., 1990; Koul et al., 2013). Studies on this topic should help to develop chemical ecology methods for pest management.

Insects have evolved a complex olfactory system to detect various odorants to search for mating partners, locate host plants, identify oviposition sites, and evade toxicants and predators (Bruce et al., 2005; Bruyne and Baker, 2008; Pelletier et al., 2015; Gadenne et al., 2016). Antennae of insects are the main organs for chemoreception and function directly in the process of sensing 
environmental information. On the antennae, a variety of sensilla are distributed, which usually contain two or more olfactory sensory neurons (OSNs) inside. Odorant receptors (ORs) are expressed on the dendritic membrane of OSNs for reception of the odorants. The external liposoluble odorant molecules penetrate the pores on the sensilla, go into the lymph, are recognized by odorant-binding proteins (OBPs), and delivered to the ORs. The ORs specifically receive the chemicals, transmitting an electrical signal to the brain, and thereby resulting in corresponding behaviors of insects (Clyne et al., 1999; Hallem et al., 2004; Zwiebel and Takken, 2004; Leal, 2013).

Odorant receptors have always been the core of olfactory research because they are essential in the odor recognition process. The first insect OR was identified in Drosophila melanogaster (Clyne et al., 1999; Gao and Chess, 1999). Compared with vertebrate ORs, which are G-protein-coupled receptors, insect ORs have the opposite membrane topology, with their $\mathrm{N}$-terminus inside and their $\mathrm{C}$-terminus outside the cell (Benton et al., 2006; Fleischer et al., 2018). The ORs identified in insects can be divided into two types: the first is the nonconventional OR, the olfactory receptor coreceptor (Orco), which is highly conserved and widely expressed among different insects; the second is the conventional OR, which varies widely among various species (Mombaerts, 1999; Benton et al., 2006). It has been widely accepted that insect ORs transduce chemical signals by forming heteromeric complexes with Orco (Sato et al., 2008; Grosse-Wilde et al., 2011).

The number of putative insect ORs identified has increased with the progress in sequencing technology and bioinformatics tools, but still varies considerably among insect species. For example, 66 ORs in Bombyx mori (Tanaka et al., 2009) and 65 ORs in Helicoverpa armigera (Zhang et al., 2015) were identified based on genome and antennal transcriptomic analysis. Moreover, 170 ORs have been found from the genome of Apis mellifera (Robertson and Wanner, 2006). The differences in the number of ORs in different insects is assumed to be driven by certain physiological and ecological demands (Fleischer et al., 2018).

As insect ORs continue to be identified, researchers have begun to study the function of ORs at the molecular and cellular levels. Many ORs in several species have been functionally analyzed by heterologous expression systems in vitro or in vivo, such as Xenopus oocyte expression system or the "empty neuron system" in Drosophila (Nakagawa et al., 2005; Wanner et al., 2010; Montagné et al., 2012; Liu et al., 2013; Cao et al., 2016; Gonzalez et al., 2016). Using these systems, functional analyses have been carried out for pheromone receptors and other general ORs in several species, including B. mori (Sakurai et al., 2004, 2011; Liu et al., 2017), D. melanogaster (Hallem et al., 2004, 2006; Kreher et al., 2005), Spodoptera littoralis (Fouchier et al., 2017), H. armigera (Liu et al., 2013; Cao et al., 2016; Chang et al., 2016; Di et al., 2017), and H. assulta (Chang et al., 2016; Cui et al., 2018).

The Asian corn borer, Ostrinia furnacalis (Lepidoptera: Crambidae), feeds on various plants including the economic crop maize, causing serious damage and resulting in about 10-30\% yield loss of maize in China (Nafus and Schreiner, 1991; Wang et al., 2000). The whole repertoire of the chemosensory genes expressed in the antennae have been identified in O. furnacalis, including 54 ORs, 24 OBPs, 19 chemosensory proteins (CSPs), 21 IRs (ionotropic receptors), 5 GRs (gustatory receptors), 2 sensory neuron membrane proteins (SNMPs), and 26 odorant degrading enzymes (ODEs) (Yang et al., 2015). Among them, ORs have been identified as essential for pheromone sensing (Yang et al., 2016). In addition, all the pheromone receptors have been functionally analyzed for understanding the details of pheromone perception in this species (Liu et al., 2018). General ORs should be considered equally important to the pheromone receptors; however, none of them have been studied in O. furnacalis.

Nonanal is a plant volatile of maize, which causes a significant electrophysiological response of gas chromatographyelectroantennographic detection (GC-EAD) in females of O. furnacalis (Zhang et al., 2018). Behavior studies have confirmed that nonanal at a certain concentration has a repellent effect on the oviposition process for female adults in this species. In this study, we identified a female-biased expressed OR that responds to the repellent nonanal using a Xenopus oocyte expression system. In addition, we found that OfurOR27 was also sensitive to two other compounds, octanal and 1-octanol, which were confirmed to be repellents in a subsequent behavioral assay. Our results provide two additional repellents for the Asian corn borer by a reverse chemical ecological method and may help to develop new approaches for controlling this pest.

\section{MATERIALS AND METHODS}

\section{Insect Rearing}

Ostrinia furnacalis colonies were maintained at laboratory conditions in the Chinese Academy of Agricultural Sciences, Beijing, China. Insects were reared on an artificial diet at $28^{\circ} \mathrm{C}$ and kept at 15:9 (L/D) and $80 \%$ relative humidity. Male and female adults were fed with $10 \%$ sugar solution. Tissues including antennae, proboscis, thorax, legs, and sex glands were dissected from 3-day-old adults, immediately placed in liquid nitrogen, and then stored at $-80^{\circ} \mathrm{C}$ until use.

\section{Plant Volatile Organic Compounds}

A total of 95 odorants from Sigma-Aldrich were used for this experiment (Supplementary Table S1) and were divided into eight groups: pheromone components, green leaf volatiles, terpenoids, aromatics, aldehydes, ketones, alcohols, and esters. All compounds were dissolved in dimethyl sulfoxide (DMSO) at a concentration of $1 \mathrm{M}$ as a stock solution. Before the experiment, the stock solution was diluted to working concentration in $1 \times$ Ringer's buffer, and $1 \times$ Ringer's buffer containing $0.1 \%$ DMSO was used as a negative control.

\section{RNA Extraction and cDNA Synthesis}

Total RNA from 50 male or female adults was isolated using TRIzol reagent (Invitrogen, Carlsbad, CA, United States) following the manufacturer's instructions. The RNA was dissolved in RNase-free water, and the integrity was assessed by gel electrophoresis. The concentration and purity of RNA were determined on a NanoDrop ND-2000 spectrophotometer 
(NanoDrop products, Wilmington, DE, United States). The firststrand complementary DNA (cDNA) was synthesized using the RevertAid First Strand cDNA Synthesis Kit (Fermentas, Vilnius, Lithuania) according to the manufacturer's instructions.

\section{Gene Cloning and Expression Vector Construction of OfurOR27}

The full-length open reading frame (ORF) encoding OfurOR27 (Acc. No. LC002721) was obtained from antennal transcriptome and was 1,206 bp in length, encoding for 402 amino acids (Yang et al., 2015). The sequence of OfurOR27 was cloned using the cDNA isolated from antennae, with primers designed by Primer 5.0 (PREMIER Biosoft International, Palo Alto, CA, United States) (Table 1). PrimeSTAR HS DNA polymerase $(2 \times$ premix) was used for the PCR reactions (TaKaRa, Dalian, China). A final volume of $50 \mu \mathrm{l}$ PCR reaction included $25 \mu \mathrm{l}$ $2 \times$ primerSTAR HS, $2 \mu \mathrm{l}$ sense and antisense primers $(10 \mathrm{mM})$, $2 \mu \mathrm{l}$ cDNA, and $19 \mu \mathrm{l}$ double-distilled $\mathrm{H}_{2} \mathrm{O}$. The PCR reactions were carried out under the following conditions: incubated at $98^{\circ} \mathrm{C}$ for $3 \mathrm{~min}$; run with 35 cycles of $98^{\circ} \mathrm{C}$ for $10 \mathrm{~s}, 55^{\circ} \mathrm{C}$ for $15 \mathrm{~s}, 72^{\circ} \mathrm{C}$ for $1 \mathrm{~min} 30 \mathrm{~s}$; and incubated at $72^{\circ} \mathrm{C}$ for $10 \mathrm{~min}$ before being held at $4^{\circ} \mathrm{C}$. The amplified PCR products were analyzed on a $1.0 \%$ agarose gel and inserted into the cloning vector pEASY-Blunt (TransGene Biotech, Beijing, China) and further sequenced to confirm the sequence. The full-length gene sequence of OfurOR27 was then ligated into a pT7Ts expression vector using a pair of newly designed primers with ApaI and XhoI restriction sites (Table 1). The pT7Ts expression vector of OfurOrco (OfurOR2) was stored at $-80^{\circ} \mathrm{C}$ (Yang et al., 2015). The accession number in DDBJ is LC002697.

\section{Functional Analysis of OfurOR27 Using a Xenopus Oocyte Ectopic Expression System}

The expression vector was linearized by restriction enzyme SmaI and subsequently used for cRNA synthesis with an mMESSAGE

TABLE 1 | Primers used in this study.

\begin{tabular}{|c|c|c|}
\hline Primers & Sequences $5^{\prime}-3^{\prime}$ & Purpose \\
\hline OfurOR27-F & ATGTCCGACATAACGCTTTC & Gene cloning \\
\hline OfurOR27-R & TTATTGTCGTTGTACATAGTGTAA & \\
\hline OfurOrco-F & ATGATGACCAAAGTGAAAGCTCAG & \\
\hline OfurOrco-R & СTACTTCAGTTGTACCAAAACCATGA & \\
\hline OfurOR27F-RT & CGCTAGCAACTATGGAACAGAC & qPCR \\
\hline OfurOR27R-RT & GGTTCCAGCAAGACAATGGTG & \\
\hline OfurActinF-RT & CCGTCCTCCTGACCGAGGCTC & \\
\hline OfurActinR-RT & GGTGTGGGAGACACCATCTCCG & \\
\hline OfurOR27F-P & $\begin{array}{l}\text { TCAGGGCCCGCCACCATGTCCGAC } \\
\text { ATAACGCTTTC }\end{array}$ & cRNA synthesizing \\
\hline OfurOR27R-P & $\begin{array}{l}\text { TCACTCGAGTTATTTGTCGTTGTACAT } \\
\text { AGTGTAA }\end{array}$ & \\
\hline OfurOrcoF-P & $\begin{array}{l}\text { TCAACTAGTGCCACCATGATGACCA } \\
\text { AAGTGAAAGCTCAG }\end{array}$ & \\
\hline OfurOrcoR-P & $\begin{array}{l}\text { TCAGCGGCCGCCTACTTCAGTTGTA } \\
\text { CCAAAACCATGA }\end{array}$ & \\
\hline
\end{tabular}

mMACHINE T7 kit (Ambion, Austin, TX, United States). Mature healthy Xenopus oocytes (stages V-VII) were incubated with $2 \mathrm{mg} / \mathrm{ml}$ collagenase I at $\mathrm{pH} 7.6$ in wash buffer consisting of $96 \mathrm{mM} \mathrm{NaCl}, 2 \mathrm{mM} \mathrm{KCl}, 5 \mathrm{mM} \mathrm{MgCl}_{2}$, and $5 \mathrm{mM} \mathrm{HEPES}$ $(\mathrm{pH} 7.6)$ at room temperature for about $1 \mathrm{~h}$ until almost all of them were separated (Liu et al., 2013). After being cultured overnight in an incubator at $18^{\circ} \mathrm{C}$, the $1: 1$ mixture of OfurOR27 and OfurOrco cRNA (27.6 ng each) was microinjected into the oocytes. After an incubation for $2-4$ days at $18^{\circ} \mathrm{C}$ in incubation medium $(1 \times$ Ringer's buffer, 5\% dialyzed horse serum, $50 \mathrm{mg} / \mathrm{ml}$ tetracycline, $100 \mathrm{mg} / \mathrm{ml}$ streptomycin, and $550 \mathrm{mg} / \mathrm{ml}$ sodium pyruvate), oocytes were connected to a twoelectrode voltage clamp, and then, the currents were recorded. Currents induced by odorants were recorded using an OC-725C oocyte clamp (Warner Instruments, Hamden, CT, United States) at a holding potential of $-80 \mathrm{mV}$. Oocytes were exposed to $10^{-4}$ concentrations of different compounds in a random order for $15 \mathrm{~s}$ each, and the interval between exposures allowed the current to return to baseline. Data acquisition and analysis were carried out with Digidata 1440A and Pclamp 10.0 software (Axon Instruments Inc., Union City, CA, United States). At the same time, dose-response data were analyzed using GraphPad Prism 7 (GraphPad Software, San Diego, CA, United States). Statistical comparison of responses to different odors of OfurOR27 was assessed using GraphPad Prism 7, followed by least-significant difference (LSD) tests.

\section{Tissue-Specific Expression of OfurOR27}

To reveal the expression level of OfurOR27 in different tissues of adults, quantitative polymerase chain reaction (qPCR) was performed using cDNA obtained from antennae (A), proboscis (P), thorax (T), legs (L), and sex glands (SG). OfurActin was chosen as the reference gene. The primers are listed in Table $\mathbf{1 .}$ GoTaq qPCR Master Mix (Promega, Madison, WI, United States) was used for $\mathrm{qPCR}$, and the reactions were carried out on an Applied Biosystems 7500 Fast Real-Time PCR System (ABI, Carlsbad, CA, United States). The reactions $(20 \mu \mathrm{l})$ consisted of $10 \mu \mathrm{l} 2 \times$ GoTaq qPCR Master Mix, $1 \mu$ l gene primer (10 mM), $1 \mu \mathrm{lcDNA}$, and $8 \mu \mathrm{l}$ RNase-free water. The conditions were $95^{\circ} \mathrm{C}$ for $2 \mathrm{~min}$; 40 cycles of $95^{\circ} \mathrm{C}$ for $15 \mathrm{~s}$; and $60^{\circ} \mathrm{C}$ for $50 \mathrm{~s}$. Each qPCR reaction was performed in triplicate with three separate biological samples to check for reproducibility. The specificity of the primers was measured using a melting curve, and the amplification efficiency was calculated using a standard curve method. OfurOR27 relative expression levels were analyzed using the relative $2^{-\Delta \mathrm{CT}}$ quantitation method, where $\Delta \mathrm{C}_{\mathrm{T}}=\mathrm{C}_{\mathrm{T}}\left(\right.$ OfurOR27) $-\mathrm{C}_{\mathrm{T}}$ (OfurActin). Statistical comparison of expression of OfurOR27 was assessed using one-way nested analysis of variance (ANOVA), followed by LSD tests.

\section{Bioassay of Oviposition in Gravid Female Adults}

Behavior analysis for oviposition was carried on for nonanal and other identified candidate odorants. A net cage $(25 \times 25 \times 25 \mathrm{~cm})$ was used with two pieces of plastic wrap $(15 \times 15 \mathrm{~cm})$ hanging on opposite sides that contained odorants and solvent, respectively. 
Each odorant was diluted into $100 \mathrm{ng} / \mu \mathrm{l}$ with paraffin oil as the solvent. Fifty gravid females were put into the cage, and after $24 \mathrm{~h}$, eggs laid on the two pieces of plastic wrap were collected and counted under a stereomicroscope (Huang et al., 2009). Three repeats were done for each odorant. The preference of oviposition was calculated as: preference $(\%)=$ eggs (odorant)/[eggs (odorants) + eggs (control)], following the methods described in Huang et al. (2009).

\section{Single-Sensillum Recording (SSR)}

Sensilla trichoidea from 2-day-old female adults were used for the recordings. Individuals were fixed in a $1 \mathrm{ml}$ plastic pipette tip and the settings for recording were the same as discribed in Liu et al. (2018). Tungsten wires were used as electrodes, one was inserted into the sensillun (recording electrode) and another was inserted into the opposite eye (reference electrode). The singlesensillum recording (SSR) system was set up with a air pulse controller CS55 and a data acquisition controller IDAC-4 made by Syntech (Kirchzarten, Germany). Recording was performed under a LEICA Z16 APO microscope at $920 \times$ magnification. AutoSpike software (V3.9, Syntech) was used to analyze the data. Odorants at the concentration of $1 \mu \mathrm{g} / \mu \mathrm{l}$ were used for the recording.

\section{Phylogenetic Analysis of OfurOR27}

For the phylogenetic analysis of genes homologous to OfurOR27, OR gene repertoires from 14 species in six orders were collected including O. furnacalis (Yang et al., 2015), H. armigera (Liu et al., 2012; Zhang et al., 2015), H. assulta (Zhang et al., 2015), B. mori (Wanner et al., 2007), Chilo suppressalis (Cao et al., 2014), Mythimna separata (Du et al., 2018), Cydia pomonella (Walker et al., 2016), Plutella xylostella (Yang et al., 2017), Manduca sexta (Koenig et al., 2015), Apis florea (Karpe et al., 2016), Locusta migratoria (Wang et al., 2015), D. melanogaster (Clyne et al., 1999; Vosshall et al., 1999; Zwiebel and Takken, 2004), Apolygus lucorum (An et al., 2016), and Acyrthosiphon pisivorum (Smadja et al., 2009). These species belong to the orders Lepidoptera, Hymenoptera, Orthoptera, Diptera, Hemiptera, and Homoptera. The amino acid sequences were aligned using MAFFT v7.130 (Katoh and Toh, 2010). The phylogenetic tree was constructed and analyzed by the maximum likelihood method using bootstrap replicates with $1,000 \times$ resampling in RAxML version 8 with the Jones-TaylorThornton amino acid substitution model (JTT) (Stamatakis, 2014). The transmembrane domains of these genes were predicted using TMHMM version $2.0^{1}$.

\section{RESULTS}

\section{OfurOR27 Responds to Nonanal, 1-Octanol, and Octanal}

In total, 95 compounds were used to identify candidate ligands of OfurOR27 with a two-electrode voltage clamp. OfurOR27 was identified as responding to nonanal but responded to eight

${ }^{1}$ http://www.cbs.dtu.dk/services/TMHMM/
TABLE 2 | Ligands identified for OfurOR27/Orco.

\begin{tabular}{|c|c|c|c|}
\hline Name & CAS. No. & $\begin{array}{l}\text { Chemical } \\
\text { formula }\end{array}$ & Structural formula \\
\hline 1-Octanol & $111-87-5$ & $\mathrm{C}_{8} \mathrm{H}_{18} \mathrm{O}$ & \\
\hline 1-Heptanol & $111-70-6$ & $\mathrm{C}_{7} \mathrm{H}_{16} \mathrm{O}$ & \\
\hline Octanal & $124-13-0$ & $\mathrm{C}_{8} \mathrm{H}_{16} \mathrm{O}$ & $\mathrm{H}^{\prime}$ \\
\hline Nonyl acetate & $143-13-5$ & $\mathrm{C}_{11} \mathrm{H}_{22} \mathrm{O}_{2}$ & $\mathrm{H}_{3} \mathrm{C}$ \\
\hline Heptanal & $111-71-7$ & $\mathrm{C}_{7} \mathrm{H}_{14} \mathrm{O}$ & \\
\hline Hexanal & $66-25-1$ & $\mathrm{C}_{6} \mathrm{H}_{12} \mathrm{O}$ & $\mathrm{CH}_{3}\left(\mathrm{CH}_{2}\right)_{3} \mathrm{CH}$ \\
\hline Nonanal & $124-19-6$ & $\mathrm{C}_{9} \mathrm{H}_{18} \mathrm{O}$ & $\mathrm{CH}_{3}\left(\mathrm{CH}_{2}\right)_{6} \mathrm{CH}_{2}$ \\
\hline Decanal & $112-31-2$ & $\mathrm{C}_{10} \mathrm{H}_{20} \mathrm{O}$ & $\mathrm{CH}_{3}\left(\mathrm{CH}_{2}\right)_{7} \mathrm{C}$ \\
\hline
\end{tabular}

CAS. No., Chemical abstracts Service number.

chemical substances in total: 1-octanol, 1-heptanol, octanal, nonyl acetate, heptanal, hexanal, nonanal, and decanal (Table 2). Among them, OfurOR27 was most sensitive to nonanal, with responses of about $328.3 \pm 41.91 \mathrm{nA}$. Moreover, OfurOR27 was also sensitive to 1-octanol and octanal, with responses of $260 \pm 36.51 \mathrm{nA}$ and $225 \pm 43.8 \mathrm{nA}$, respectively $(p<0.01$ one-way ANOVA followed LSD test, $n=6$ ) (Figure 1). The dose-response study confirmed the sensitivity of OfurOR27 to nonanal, 1-octanol, and octanal, with the EC50 value of $3.673 \times 10^{-7} \mathrm{M}, 1.406 \times 10^{-5} \mathrm{M}$, and $1.184 \times 10^{-6} \mathrm{M}$, respectively (Figure 1D). Response values to 1-heptanol, nonyl acetate, heptanal, hexanal, and decanal were not as high, at only $\sim 100$ nA (Figures 1A-C).

\section{Tissue Expression Profiles of OfurOR27}

The tissue-specific expression analysis indicated that OfurOR27 was predominantly expressed in the antennae of adults, with relative expression levels of more than 0.1 , compared to those in proboscis, thorax, legs, and sex glands, with the relative expression levels of $0.00291,0.00192,0.00223$, and 0.00255 , respectively (Figure 2). Moreover, OfurOR27 showed femalebiased expression in the antennae, which was consistent with a previous study (Yang et al., 2015).

\section{Nonanal, 1-Octanol, and Octanal Are Repellents for 0 . furnacalis}

Ostrinia furnacalis females laid fewer eggs on the plastic containing nonanal. This result was consistent with a previous study (Zhang et al., 2018). In addition, we identified that 1octanol and octanal also had a repellent effect causing females to avoid laying eggs while these odorants were present. The preference rates of nonanal, 1-octanol, and octanal were 39.7, 17.3, and 38.8\%, respectively (Figure 3). Among them, 1-octanol displayed a better effect as a repellent to oviposition for O. furnacalis females. 
A

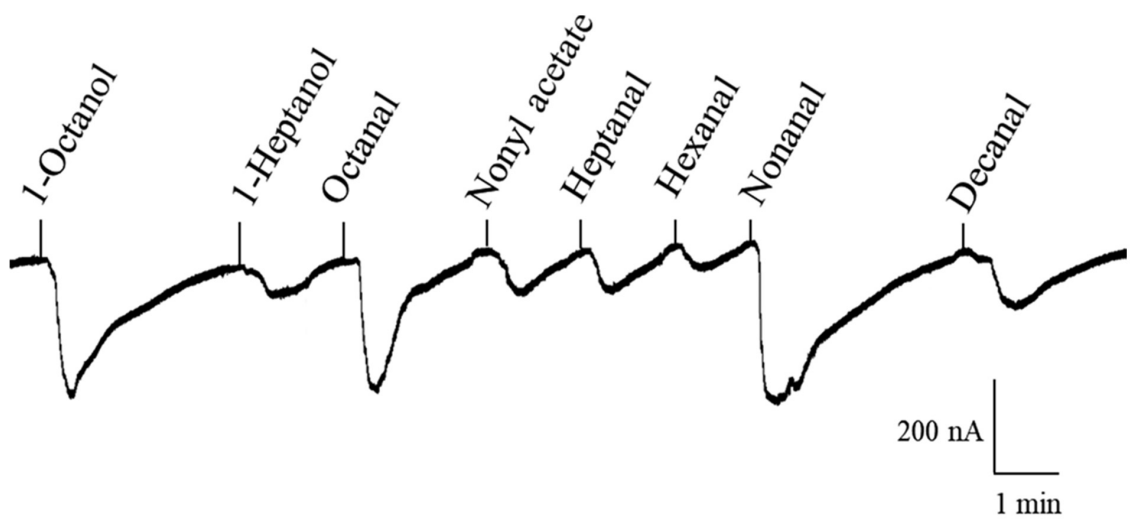

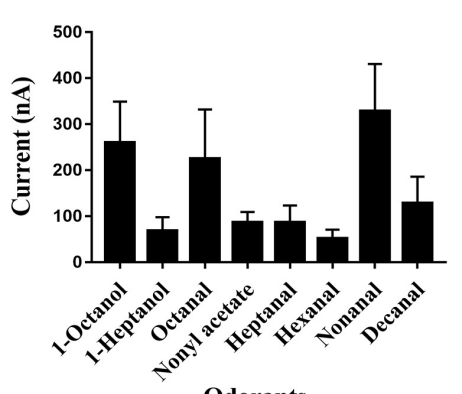

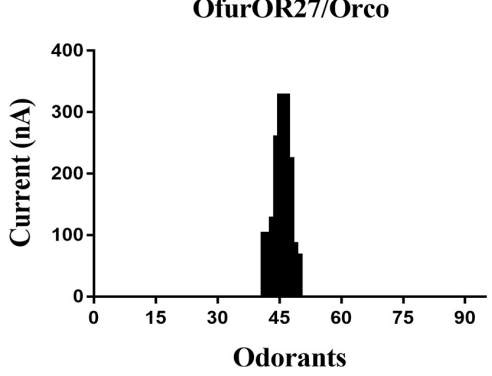

D

Nonanal (M)
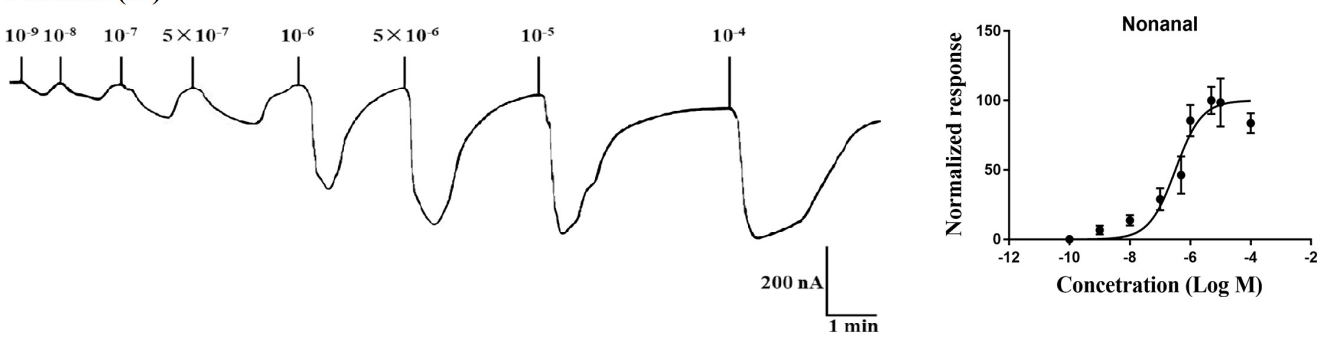

1-octanol (M)
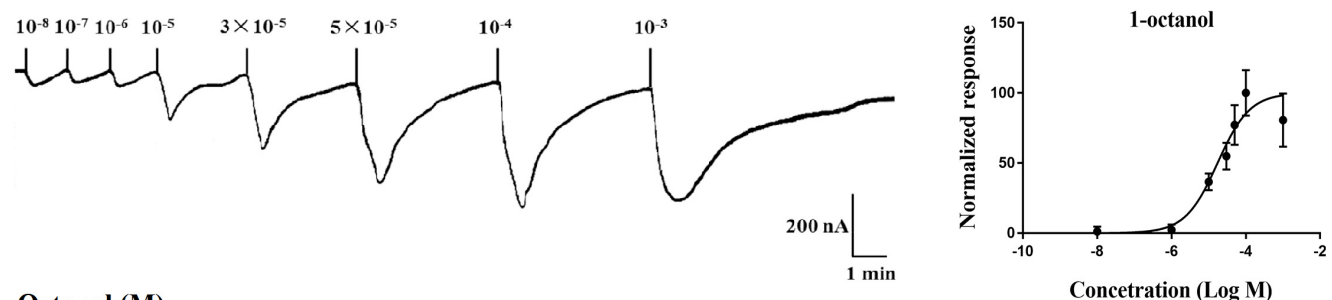

Octanal (M)
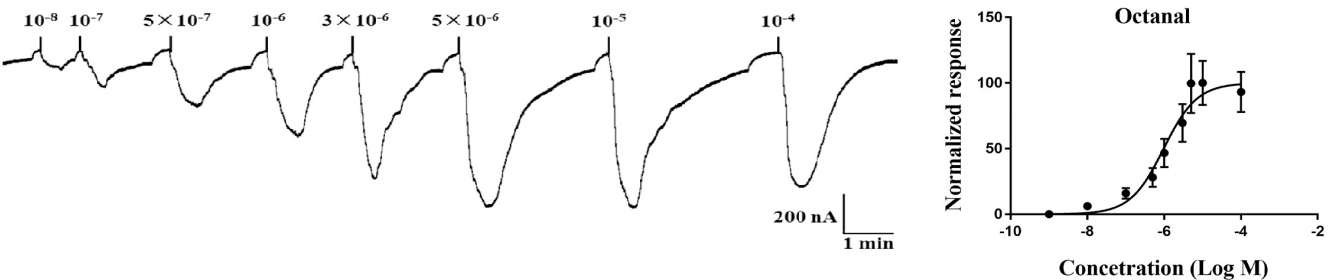

FIGURE 1 | Functional analysis of OfurOR27 using a Xenopus oocyte expression system. (A) Responses of OfurOR27/Orco to eight identified odorants (10-4 M). (B) Response profile of OfurOR27/Orco. Error bars indicate standard error of the mean [ $p<0.001$, ANOVA, least-significant difference (LSD), $n=6]$. (C) Tuning curve for the OfurOR27/Orco to an odorant panel comprising 95 odorants, arranged along the $x$-axis according to the strength of the response they elicit. The odorants that elicited the strongest responses were placed near the center of the distribution, while those that elicited the weakest responses were placed near the edges. (D) Dose-response curve for OfurOR27/Orco in responding to nonanal, 1-octanol, and octanal. Error bars indicate SEM $(n=6)$. 


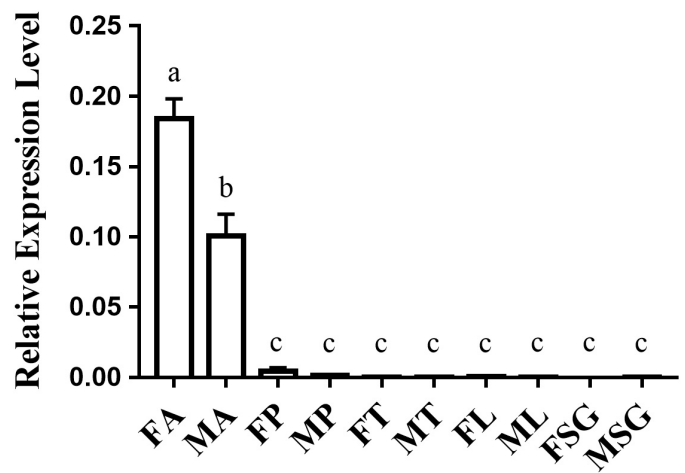

FIGURE 2 | Tissue-specific expression of OfurOR27 in O. furnacalis. FA, female antennae; MA, male antennae; FP, female proboscis; MP, male proboscis; FT, female thorax; MT, male thorax; FL, female legs; ML, male legs; FSG, female sex glands; MSG, male sex glands. Error bars represent the standard error; those labeled with different letters are significantly different $[p<0.05$, ANOVA, least-significant difference (LSD)].
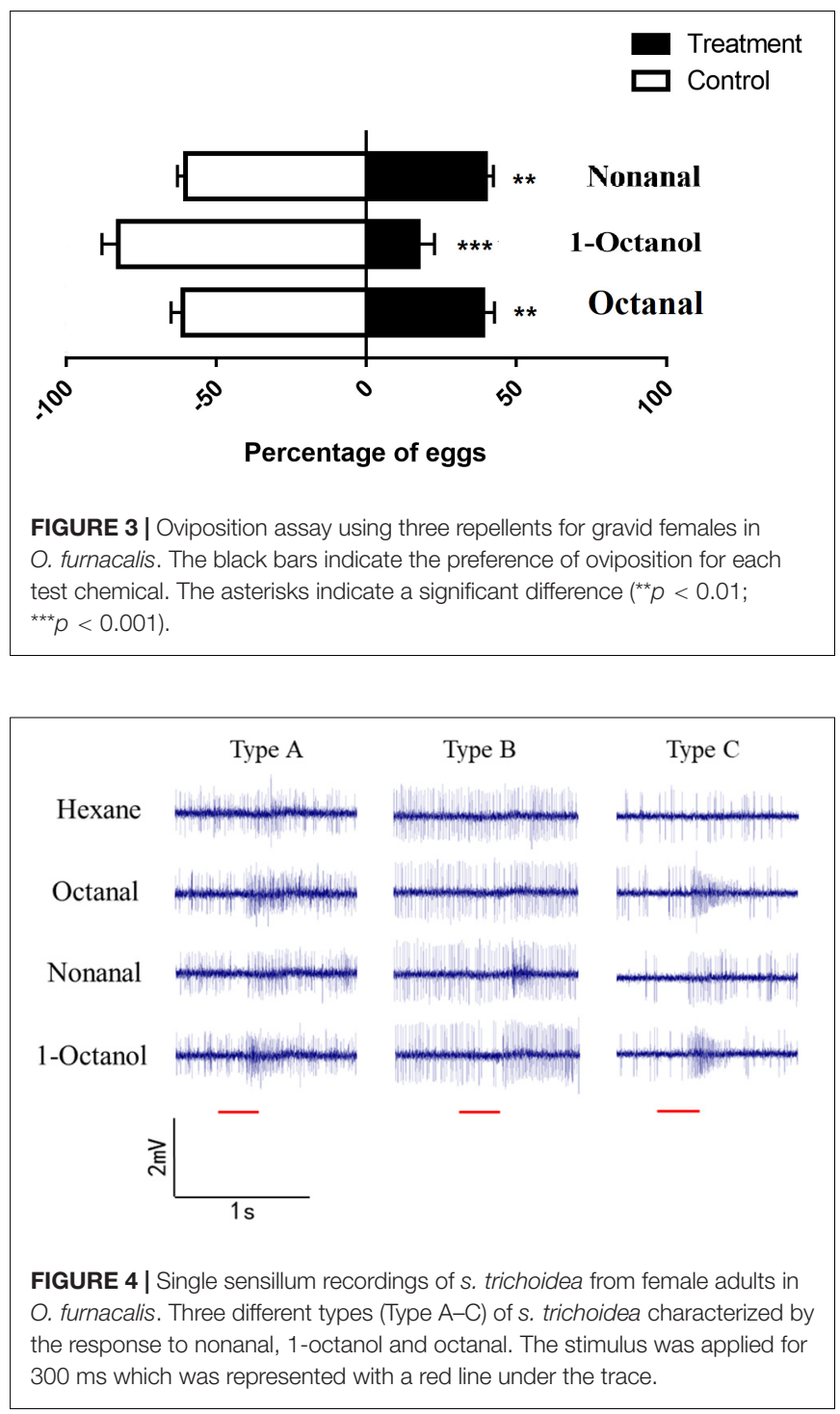

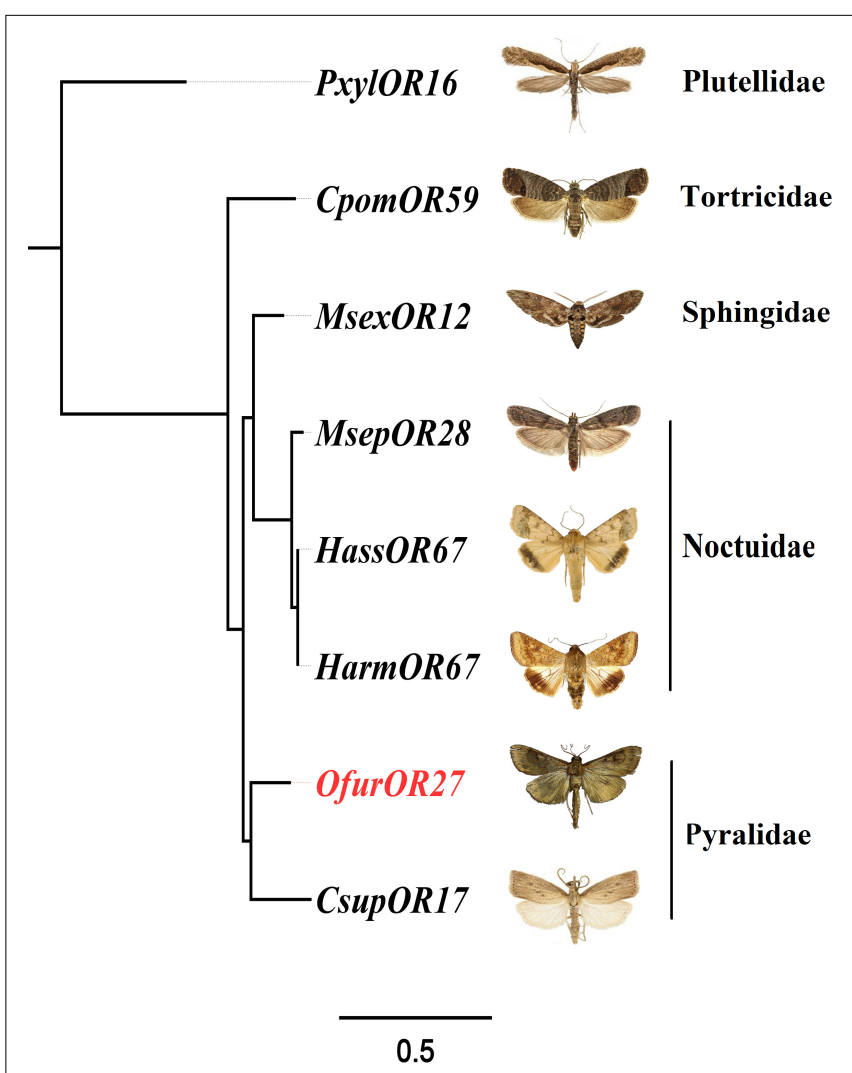

FIGURE 5 | Phylogenetic analysis for OfurOR27 and its homologous genes. Odorant receptors including PxylOR16, MsexOR12, MsepOR28, HassOR67, HarmOR67, CsupOR17, and CpomOR59 (Supplementary Dataset S1) were downloaded from the National Center for Biotechnology Information. All sequences were aligned using MAFFT software. The phylogenetic analysis was conducted by RAxML version 8. The final tree was visualized by FigTree version 1.4.0 software (http://tree.bio.ed.ac.uk/software/figtree/).

\section{Single-Sensillum Recording for Nonanal, 1-Octanol, and Octanal}

Sensilla trichoidea were used for SSR in O. furnacalis. Most of the recorded sensilla did not respond to nonanal, 1-octanol, or octanal. Three types of sensilla responded to the odorants (Figure 6). Type A is a short sensilla trichoidea mainly distributed on the side of the female antennae, while types $\mathrm{B}$ and $\mathrm{C}$ are long sensilla trichoidea at the center of the female antennae. Type C responded to nonanal, 1-octanol, and octanal. Type A responded to 1-octanol and octanal. Type B seemed to only respond to nonanal, but we only recorded it once, possibly due to interference by insect movement.

\section{Phylogenetic Analysis of Homologous Genes of OfurOR27}

To identify homologous genes of OfurOR27, phylogenetic analysis was carried out with 1,075 ORs from 14 species. Seven ORs clustered into the same clade with OfurOR27, including PxylOR16, MsexOR12, MsepOR28, HassOR67, HarmOR67, CsupOR17, and CPOmOR59 from five families in Lepidoptera (Figure 4). Homologous genes were only found in lepidoptera 


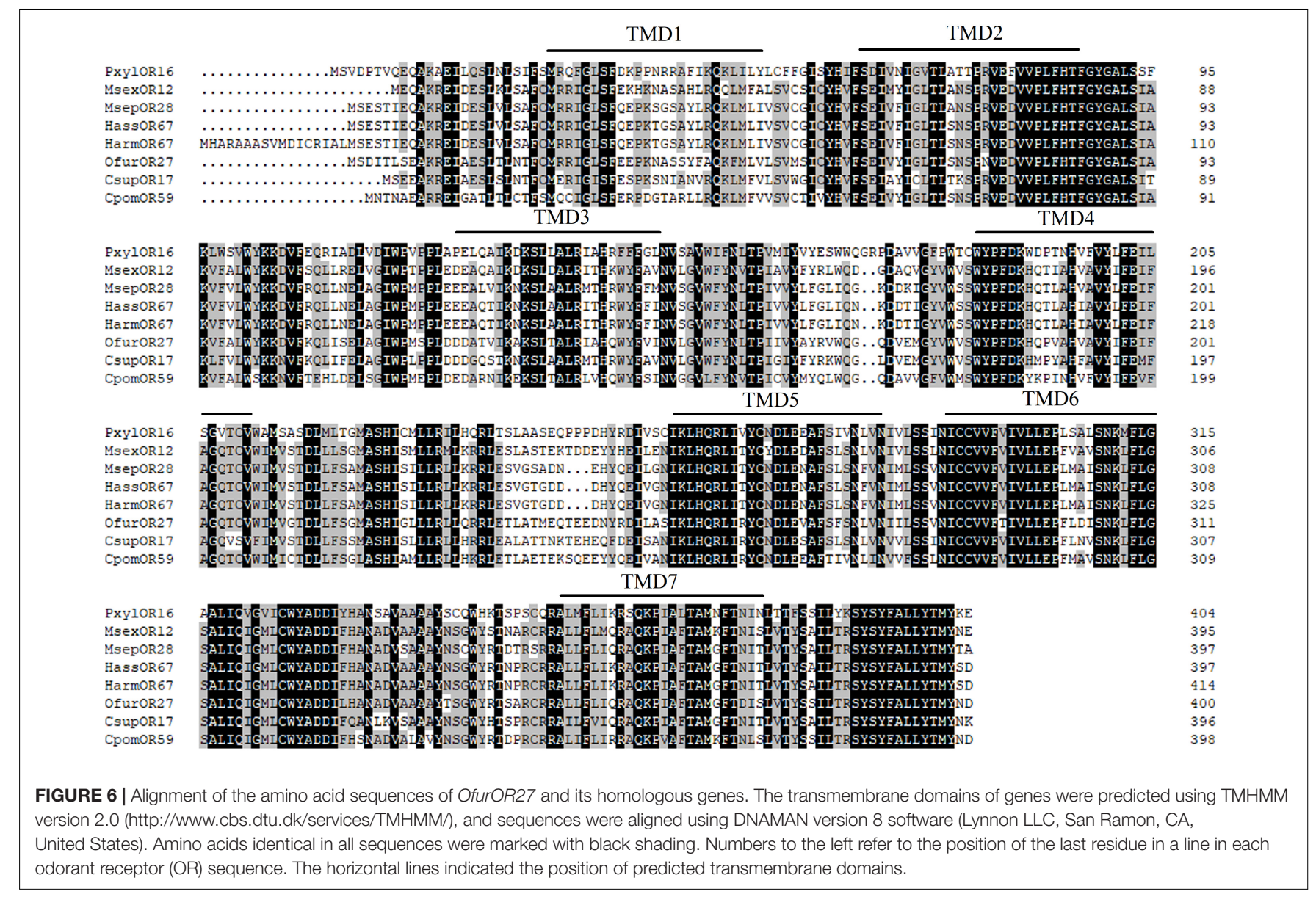

insects, but no homologous genes were found in B. mori. We speculated that degradation may have occurred in B. mori. All the homologous genes were aligned with OfurOR27. The correlation prediction software was used to predict the number of transmembrane structures of seven ORs, and the results showed that they all have seven transmembrane domains and the $\mathrm{N}$-terminus was located within the cell membrane (Figure 5). Sequence alignment of OfurOR27 with its seven orthologous genes showed that they shared $77.56 \%$ amino acid identity. Moreover, PxylOR16, MsexOR12, MsepOR28, HassOR67, HarmOR67, CsupOR17, and CpomOR59 were aligned with OfurOR27 and found to have 56.67, 73.81, 69.29, 70, 70, 72.62 , and $69.52 \%$ identity, respectively.

\section{DISCUSSION}

Use of chemical pesticides is still the primary approach for controlling pests. Integrated pest management (IPM) has been strongly advocated in modern agriculture. The new approach of pest management using chemical ecology is an important part of IPM. Attractants such as pheromones have been applied controlling various pests due to a high degree of commercialization. For repellents, only a few compounds have been made as commercial products. The most famous odorant is $\mathrm{N}, \mathrm{N}$-diethyl-m-toluamide (DEET), which was an effective broad-spectrum mosquito repellent (Bressac and Chevrier, 1998). However, most of these repellents were identified for controlling pests of human health concern such as mosquitos and cockroaches (Li and Boyaro, 2002). For agricultural pests, the "pull and push" strategy was favored. In this strategy, researchers combined attractants and repellents together to control pests (Miller and Cowles, 1990). Recently, herbivoreinduced plant volatiles were identified to mediate tritrophic interactions (Turlings and Erb, 2018). This research opened a new approach for pest management through chemical ecology.

Olfaction allows insects to distinguish chemical signals to complete a series of behaviors, such as locating food, sexual partners, and oviposition sites. To successfully perform these behaviors, the sensitive olfactory system of insects must respond to chemical stimuli at the appropriate time (Gadenne et al., 2016). Previous studies have shown that some general ORs may be involved in the common behaviors in both males and females (Zhang et al., 2013), whereas other ORs with biased expression in females or males may be involved in sex-specific behaviors (Anderson et al., 2009; Liu et al., 2014; Yan et al., 2015). Plant volatiles such as linalool, benzoic acid, and 2-phenylethanol have been used as oviposition clues for some female moths (Røstelien et al., 2005; Anderson et al., 2009). Some ORs are functionally characterized as receptors to these key compounds 
(Anderson et al., 2009; Jordan et al., 2009). OR4 from domestic mosquitoes selectively responds to the released odor of humans and functions directly in host identification and blood sucking (McBride et al., 2014). AlucOR46 might be related to locate the host plants of Apolygus lucorum (Zhang et al., 2016). However, many other ORs are still orphans, and we lack overall awareness of how insects detect plant volatiles.

In this study, we identified an OR with female-biased expression that responds to the repellent nonanal using a Xenopus oocyte expression system. In addition, we found that OfurOR27 was also sensitive to two other compounds, octanal and 1-octanol, which were confirmed to be repellents by a subsequent behavioral assay. Single-sensillum recordings were conducted for nonanal, octanal, and 1-octanol, and indicated that OfurOR27 may be expressed on the sensilla trichoidea. Octanal is a plant green leaf compound, which was confirmed to significantly repel mosquitoes (Logan et al., 2010). Moreover, 1-octanol, an aroma component of tea, may not be a repellent for pest, but it is an attractant for natural enemies Sphaerophoria menthastri and Chrysopa pallens in tea gardens (Han and Zhou, 2004). Phylogenetic analysis showed that some pest species have genes homologous to OfurOR27, which might indicate that they have similar functions and that all three repellents might be applied in other species.

Above all, our results indicated that OfurOR27 is one of the corresponding ORs for nonanal, octanal, and 1-octanol, which all negatively affect $O$. furnacalis. A further study should be carried out to identify other ORs that respond to the three repellents to clarify the molecular mechanism of chemosensation for each odorant. Using reverse chemical ecology, we determined that OfurOR27 is a common receptor for repellents and found two additional repellents for O. furnacalis, which may contribute to developing environment-friendly approaches to control this maize pest.

\section{REFERENCES}

An, X. K., Sun, L., Liu, H. W., Liu, D. F., Ding, Y. X., Li, L. M., et al. (2016). Identification and expression analysis of an olfactory receptor gene family in green plant bug Apolygus lucorum (Meyer-Dür). Sci. Rep. 6:37870. doi: 10 . 1038/srep37870

Anderson, A. R., Wanner, K. W., Trowell, S. C., Warr, C. G., Jaquin-Joly, E., Zagatti, P., et al. (2009). Molecular basis of female-specific odorant responses in Bombyx mori. Insect. Biochem. Mol. Biol. 39, 189-197. doi: 10.1016/j.ibmb.2008.11.002

Benton, R., Sachse, S., Michnick, S. W., and Vosshall, L. B. (2006). Atypical membrane topology and heteromeric function of Drosophila odorant receptors in vivo. PLoS Biol. 4:e20. doi: 10.1371/journal.pbio.0040020

Bressac, C., and Chevrier, C. (1998). Offspring and sex ratio are independent of sperm management in Eupelmus orientalis females. J. Insect Physiol. 44, 351-359. doi: 10.1016/s0022-1910(97)00119-4

Bruce, T. J., Wadhams, L. J., and Woodcock, C. M. (2005). Insect host location: a volatile situation. Trends Plant Sci. 10, 269-274. doi: 10.1016/j.tplants.2005. 04.003

Bruyne, M. D., and Baker, T. C. (2008). Odor detection in insects: volatile codes. J. Chem. Ecol. 34, 882-897. doi: 10.1007/s10886-008-9485-4

Cao, D., Liu, Y., Wei, J., Liao, X., Walker, W. B., Li, J., et al. (2014). Identification of Candidate Olfactory Genes in Chilo suppressalis by Antennal Transcriptome Analysis. Int. J. Biol. Sci. 10, 846-860. doi: 10.7150/ijbs.9297

Cao, S., Liu, Y., Guo, M., and Wang, G. (2016). A conserved odorant receptor tuned to floral volatiles in three heliothinae species. PLoS One 11:e0155029. doi: 10.1371/journal.pone.0155029

\section{DATA AVAILABILITY STATEMENT}

The data relating to OfurOR27 (LC002721) may be accessed from the DDBJ website: http://getentry.ddbj.nig.ac.jp/getentry/na/ LC002721/?format $=$ flatfile $\&$ filetype $=$ html\&trace $=$ true\&show suppressed $=$ false $\&$ limit $=10$.

\section{AUTHOR CONTRIBUTIONS}

GW and BY designed the experiments. JY, YC, and YZ carried out the experiments. JY and BY analyzed the experimental results. JY and BY wrote the manuscript.

\section{FUNDING}

This work was supported by the National Natural Science Foundation of China (31701859, 31725023, and 31621064).

\section{ACKNOWLEDGMENTS}

We thank Song Cao, Yipeng Liu, and Nana Ma (Institute of Plant Protection, Chinese Academy of Agricultural Sciences) for help with molecular biology experiments. We thank Ms. Qiuyan Wang (Institute of Plant Protection, Chinese Academy of Agricultural Sciences) for rearing insects.

\section{SUPPLEMENTARY MATERIAL}

The Supplementary Material for this article can be found online at: https://www.frontiersin.org/articles/10.3389/fphys. 2020.00176/full\#supplementary-material

Chang, H., Guo, M., Wang, B., Liu, Y., Dong, S., and Wang, G. (2016). Sensillar expression and responses of olfactory receptors reveal different peripheral coding in two Helicoverpa species using the same pheromone components. Sci. Rep. 6:18742. doi: 10.1038/srep 18742

Clyne, P. J., Warr, C. G., Freeman, M. R., Lessing, D., Kim, J., and Carlson, J. R. (1999). A novel family of divergent seven-transmembrane proteins: candidate odorant receptors in Drosophila. Neuron 22, 327-338. doi: 10.1016/s08966273(00)81093-4

Cui, W. C., Wang, B., Guo, M. B., Liu, Y., Jacquin-Joly, E., Yan, S. C., et al. (2018). A receptor-neuron correlate for the detection of attractive plant volatiles in Helicoverpa assulta (Lepidoptera: Noctuidae). Insect Biochem. Mol. Biol. 97, 31-39. doi: 10.1016/j.ibmb.2018.04.006

Di, C., Ning, C., Huang, L. Q., and Wang, C. Z. (2017). Design of larval chemical attractants based on odorant response spectra of odorant receptors in the cotton bollworm. Insect Biochem. Mol. Biol. 84, 48-62. doi: 10.1016/j.ibmb.2017. 03.007

Du, L., Zhao, X., Liang, X., Gao, X., Liu, Y., and Wang, G. (2018). Identification of candidate chemosensory genes in Mythimna separata by transcriptomic analysis. BMC Genom. 19:518. doi: 10.1186/s12864-018-4898-0

Fleischer, J., Pregitzer, P., Breer, H., and Krieger, J. (2018). Access to the odor world: olfactory receptors and their role for signal transduction in insects. Cell. Mole. Life Sci. 75, 485-508. doi: 10.1007/s00018-017-2627-5

Fouchier, A. D., Walker, W. B., Montagné, N., Steiner, C., Binyameen, M., Schlyter, F., et al. (2017). Functional evolution of Lepidoptera olfactory receptors revealed by deorphanization of a moth repertoire. Nat. Commun. 8, 15709. doi: $10.1038 /$ ncomms 15709 
Gadenne, C., Barrozo, R. B., and Anton, S. (2016). Plasticity in Insect Olfaction: To Smell or Not to Smell? Annu. Rev. Entomol. 61, 317-333. doi: 10.1146/annurevento-010715-023523

Gao, Q., and Chess, A. (1999). Identification of candidate Drosophila olfactory receptors from genomic DNA sequence. Genomics 60, 31-39. doi: 10.1006/ geno.1999.5894

Gonzalez, F., Witzgall, P., and Walker Iii, W. B. (2016). Protocol for heterologous expression of insect odourant receptors in Drosophila. Front. Ecol. Evol. 4:24. doi: $10.3389 /$ fevo.2016.00024

Gregg, P. C., Del Socorro, A. P., and Henderson, G. S. (2010). Development of a synthetic plant volatile-based attracticide for female noctuid moths. II. Bioassays of synthetic plant volatiles as attractants for the adults of the cotton bollworm, Helicoverpa armigera (Hübner)(Lepidoptera: Noctuidae). Austr. J. Entomol. 49, 21-30. doi: 10.1111/j.1440-6055.2009.00734.x

Grosse-Wilde, E., Kuebler, L. S., Bucks, S., Vogel, H., Wicher, D., and Hansson, B. S. (2011). Antennal transcriptome of Manduca sexta. Proc. Nat. Acad. Sci. 108, 7449-7454. doi: 10.1073/pnas.1017963108

Hallem, E. A., Dahanukar, A., and Carlson, J. R. (2006). Insect odor and taste receptors. Annu. Rev. Entomol. 51, 113-135. doi: 10.1146/annurev.ento.51. 051705.113646

Hallem, E. A., Ho, M. G., and Carlson, J. R. (2004). The molecular basis of odor coding in the Drosophila antenna. Cell 117, 965-979. doi: 10.1016/j.cell.2004. 05.012

Han, B., and Zhou, C. (2004). The attraction of major volatiles from tea leaves and Camellia to the Sphaerophoria menthastri and Chrysopa pallens. Chin. J. Appl. Ecol. 4, 623-626.

Huang, C. H., Yan, F. M., Byers, J. A., Wang, R. J., and Xu, C. R. (2009). Volatiles induced by the larvae of the Asian corn borer (Ostrinia furnacalis) in maize plants affect behavior of conspecific larvae and female adults. Insect Sci. 16, 311-320. doi: 10.1111/j.1744-7917.2009.01257.x

Jordan, M. D., Anderson, A., Begum, D., Carraher, C., Authier, A., Marshall, S. D., et al. (2009). Odorant receptors from the light brown apple moth (Epiphyas postvittana) recognize important volatile compounds produced by plants. Chem. Sen. 34, 383-394. doi: 10.1093/chemse/ bjp010

Karpe, S. D., Jain, R., Brockmann, A., and Sowdhamini, R. (2016). Identification of complete repertoire of Apis florea odorant receptors reveals complex orthologous relationships with Apis mellifera. Genome. Biol. Evol. 8, 2879-2895. doi: $10.1093 / \mathrm{gbe} / \mathrm{evw} 202$

Katoh, K., and Toh, H. (2010). Parallelization of the MAFFT multiple sequence alignment program. Bioinformatics 26, 1899-1900. doi: 10.1093/bioinformatics/ btq224

Koenig, C., Hirsh, A., Bucks, S., Klinner, C., Vogel, H., Shukla, A., et al. (2015). A reference gene set for chemosensory receptor genes of Manduca sexta. Insect Biochem. Mol. Biol. 66, 51-63. doi: 10.1016/j.ibmb.2015.09.007

Koul, O., Singh, R., Kaur, B., and Kanda, D. (2013). Comparative study on the behavioral response and acute toxicity of some essential oil compounds and their binary mixtures to larvae of Helicoverpa armigera, Spodoptera litura and Chilo partellus. Indust. Crops Products 49, 428-436. doi: 10.1016/j.indcrop. 2013.05.032

Kreher, S. A., Kwon, J. Y., and Carlson, J. R. (2005). The molecular basis of odor coding in the Drosophila larva. Neuron 46, 445-456. doi: 10.1016/j.neuron. 2005.04.007

Leal, W. S. (2013). Odorant reception in insects: roles of receptors, binding proteins, and degrading enzymes. Annu. Rev. Entomol. 58, 373-391. doi: 10. 1146/annurev-ento-120811-153635

Li, Q., and Boyaro. (2002). Past, present and future of insect repellents. Modern Agrochem. 5,

Liu, C., Liu, Y., Guo, M., Cao, D., Dong, S., and Wang, G. (2014). Narrow tuning of an odorant receptor to plant volatiles in Spodoptera exigua (H übner). Insect Mole. Biol. 23, 487-496. doi: 10.1111/imb.12096

Liu, Q., Liu, W., Zeng, B., Wang, G., Hao, D., and Huang, Y. (2017). Deletion of the Bombyx mori odorant receptor co-receptor (BmOrco) impairs olfactory sensitivity in silkworms. Insect Biochem. Mole. Biol. 86, 58-67. doi: 10.1016/j. ibmb.2017.05.007

Liu, W., Jiang, X. C., Cao, S., Yang, B., and Wang, G. R. (2018). Functional studies of sex pheromone receptors in asian corn borer Ostrinia furnacalis. Front. Physiol. 9:591. doi: 10.3389/fphys.2018.00591
Liu, Y., Gu, S., Zhang, Y., Guo, Y., and Wang, G. (2012). Candidate olfaction genes identified within the Helicoverpa armigera antennal transcriptome. PLoS One 7:e48260. doi: 10.1371/journal.pone.0048260

Liu, Y., Liu, C., Lin, K., and Wang, G. (2013). Functional specificity of sex pheromone receptors in the cotton bollworm Helicoverpa armigera. PLoS One 8:e62094. doi: 10.1371/journal.pone.0062094

Logan, J. G., Stanczyk, N. M., Hassanali, A., Kemei, J., Santana, A. E., Ribeiro, K. A., et al. (2010). Arm-in-cage testing of natural human-derived mosquito repellents. Mal. J. 9:239. doi: 10.1186/1475-2875-9-239

McBride, C. S., Baier, F., Omondi, A. B., Spitzer, S. A., Lutomiah, J., Sang, R., et al. (2014). Evolution of mosquito preference for humans linked to an odorant receptor. Nature 515:222. doi: 10.1038/nature13964

Miller, J. R., and Cowles, R. S. (1990). Stimulo-deterrent diversion: a concept and its possible application to onion maggot control. J. Chem. Ecol. 16, 3197-3212. doi: 10.1007/BF00979619

Mitchell, E. R., Tingle, P. C., and Heath, R. R. (1990). Ovipositional response of three Heliothis species (Lepidoptera: Noctuidae) to allelochemicals from cultivated and wild host plants. J. Chem. Ecol. 16, 1817-1827. doi: 10.1007/ bf01020496

Mombaerts, P. (1999). Molecular biology of odorant receptors in vertebrates. Annu. Rev. Neurosci. 22, 487-509. doi: 10.1146/annurev.neuro.22.1.487

Montagné, N., Chertemps, T., Brigaud, I., François, A., François, M. C., De Fouchier, A., et al. (2012). Functional characterization of a sex pheromone receptor in the pest moth Spodoptera littoralis by heterologous expression in Drosophila. Eur. J. Neurosci. 36, 2588-2596. doi: 10.1111/j.1460-9568.2012. 08183.x

Nafus, D. M., and Schreiner, I. H. (1991). Review of the biology and control of the Asian corn borer, Ostrinia furnacalis (Lep: Pyralidae). Int. J. Pest Manag. 37, 41-56. doi: 10.1080/09670879109371535

Nakagawa, T., Sakurai, T., Nishioka, T., and Touhara, K. (2005). Insect sexpheromone signals mediated by specific combinations of olfactory receptors. Science 307, 1638-1642. doi: 10.1126/science.1106267

Pelletier, J., Xu, P., Yoon, K. S., Clark, J. M., and Leal, W. S. (2015). Odorant receptor-based discovery of natural repellents of human lice. Insect Biochem. Mole. Biol. 66, 103-109. doi: 10.1016/j.ibmb.2015.10.009

Robertson, H. M., and Wanner, K. W. (2006). The chemoreceptor superfamily in the honey bee, Apis mellifera: expansion of the odorant, but not gustatory, receptor family. Genome Res. 16, 1395-1403. doi: 10.1101/gr.5057506

Røstelien, T., Stranden, M., Borg-Karlson, A. K., and Mustaparta, H. (2005). Olfactory receptor neurons in two heliothine moth species responding selectively to aliphatic green leaf volatiles, aromatic compounds, monoterpenes and sesquiterpenes of plant origin. Chem. Senses 30, 443-461. doi: 10.1093/ chemse/bji039

Sakurai, T., Mitsuno, H., Haupt, S. S., Uchino, K., Yokohari, F., Nishioka, T., et al. (2011). A single sex pheromone receptor determines chemical response specificity of sexual behavior in the silkmoth Bombyx mori. PLoS Genetics 7:e1002115. doi: 10.1371/journal.pgen.1002115

Sakurai, T., Nakagawa, T., Mitsuno, H., Mori, H., Endo, Y., Tanoue, S., et al. (2004). Identification and functional characterization of a sex pheromone receptor in the silkmoth Bombyx mori. Proc. Nat. Acad. Sci. 101, 16653-16658. doi: 10.1073/pnas.0407596101

Sato, K., Pellegrino, M., Nakagawa, T., Nakagawa, T., Vosshall, L. B., and Touhara, K. (2008). Insect olfactory receptors are heteromeric ligand-gated ion channels. Nature 452, 1002. doi: 10.1038/nature06850

Smadja, C., Shi, P., Butlin, R. K., and Robertson, H. M. (2009). Large gene family expansions and adaptive evolution for odorant and gustatory receptors in the pea aphid. Acyrthosiphon pisum. Mol. Biol. Evol. 26, 2073-2086. doi: 10.1093/ molbev/msp116

Stamatakis, A. (2014). RAxML version 8: a tool for phylogenetic analysis and post-analysis of large phylogenies. Bioinformatics 30, 1312-1313. doi: 10.1093/ bioinformatics/btu033

Tanaka, K., Uda, Y., Ono, Y., Nakagawa, T., Suwa, M., Yamaoka, R., et al. (2009). Highly selective tuning of a silkworm olfactory receptor to a key mulberry leaf volatile. Curr. Biol. 21:623. doi: 10.1016/j.cub.2011.03.046

Turlings, T. C. J., and Erb, M. (2018). Tritrophic interactions mediated by herbivore-induced plant volatiles: mechanisms, ecological relevance, and application potential. Annu. Rev. Entomol. 63, 433-452. doi: 10.1146/annurevento-020117-043507 
Vosshall, L. B., Amrein, H., Morozov, P. S., Rzhetsky, A., and Axel, R. (1999). A spatial map of olfactory receptor expression in the Drosophila antenna. Cell 96, 725-736. doi: 10.1016/s0092-8674(00)80582-6

Walker III, W. B., Gonzalez, F., Garczynski, S. F., and Witzgall, P. (2016). The chemosensory receptors of codling moth Cydia pomonella - expression in larvae and adults. Sci. Rep. 6:23518. doi: 10.1038/srep23518

Wang, Z., Lu, X., He, K., and Zhou, D. (2000). Review of history, present situation and prospect of the Asian maize borer research in China. Yournal of Shenyang Agricult. University 31, 402-412.

Wang, Z., Yang, P., Chen, D., Jiang, F., Li, Y., Wang, X., et al. (2015). Identification and functional analysis of olfactory receptor family reveal unusual characteristics of the olfactory system in the migratory locust. Cell. Mol. Life Sci. 72, 4429-4443. doi: 10.1007/s00018-015-2009-9

Wanner, K., Anderson, A., Trowell, S., Theilmann, D., Robertson, H. M., and Newcomb, R. (2007). Female-biased expression of odourant receptor genes in the adult antennae of the silkworm. Bombyx mori. Insect Mol Biol. 16, 107-119. doi: 10.1111/j.1365-2583.2007.00708.x

Wanner, K. W., Nichols, A. S., Allen, J. E., Bunger, P. L., Garczynski, S. F., Linn, C. E. Jr., et al. (2010). Sex pheromone receptor specificity in the European corn borer moth. Ostrinia nubilalis. PLoS One 5:e8685. doi: 10.1371/journal.pone. 0008685

Witzgall, P., Kirsch, P., and Cork, A. (2010). Sex Pheromones and Their Impact on Pest Management. J. Chem. Ecol. 36, 80-100. doi: 10.1007/s10886-009-9737-y

Yan, S. W., Zhang, J., Liu, Y., Li, G. Q., and Wang, G. R. (2015). An olfactory receptor from Apolygus lucorum (Meyer-Dur) mainly tuned to volatiles from flowering host plants. J. Insect Physiol. 79, 36-41. doi: 10.1016/j.jinsphys.2015. 06.002

Yang, B., Fujii, T., Ishikawa, Y., and Matsuo, T. (2016). Targeted mutagenesis of an odorant receptor co-receptor using TALEN in Ostrinia furnacalis. Insect Biochem. Mol. Biol. 70, 53-59. doi: 10.1016/j.ibmb.2015.12.003

Yang, B., Ozaki, K., Ishikawa, Y., and Matsuo, T. (2015). Identification of candidate odorant receptors in asian corn borer Ostrinia furnacalis. PLoS One 10:e0121261. doi: 10.1371/journal.pone.0121261
Yang, S., Cao, D., Wang, G., and Liu, Y. (2017). Identification of genes involved in chemoreception in Plutella xyllostella by antennal transcriptome analysis. Scienti. Rep. 7:11941. doi: 10.1038/s41598-017-11646-7

Zhang, J., Liu, C., Yan, S., Liu, Y., Guo, M., Dong, S., et al. (2013). An odorant receptor from the common cutworm (Spodoptera litura) exclusively tuned to the important plant volatile cis-3-H exenyl acetate. Insect Mole. Biol. 22, 424-432. doi: 10.1111/imb.12033

Zhang, J., Wang, B., Dong, S., Cao, D., Dong, J., Walker, W. B., et al. (2015). Antennal transcriptome analysis and comparison of chemosensory gene families in two closely related noctuidae moths. Helicoverpa armigera and H. assulta. PLoS One 10:e0117054. doi: 10.1371/journal.pone.011 7054

Zhang, W., Wang, W., Bai, S., Zhang, T., He, K., and Wang, Z. (2018). ). Screening of host plants for spawning preference of females of Asian corn borer and electrophysiological responses to volatile chemical constituents of Valeriana. Acta Entomol. Sin. 61, 224-231.

Zhang, Z., Zhang, M., Yan, S., Wang, G., and Liu, Y. (2016). A female-biased odorant receptor from Apolygus lucorum (Meyer-Dür) tuned to some plant odors. Int. J. Mol. Sci. 17:1165. doi: 10.3390/ijms17081165

Zwiebel, L., and Takken, W. (2004). Olfactory regulation of mosquito-host interactions. Insect Biochem. Mol. Biol 34, 645-652. doi: 10.1016/j.ibmb.2004. 03.017

Conflict of Interest: The authors declare that the research was conducted in the absence of any commercial or financial relationships that could be construed as a potential conflict of interest.

Copyright (c) $2020 \mathrm{Yu}$, Yang, Chang, Zhang and Wang. This is an open-access article distributed under the terms of the Creative Commons Attribution License (CC BY). The use, distribution or reproduction in other forums is permitted, provided the original author(s) and the copyright owner(s) are credited and that the original publication in this journal is cited, in accordance with accepted academic practice. No use, distribution or reproduction is permitted which does not comply with these terms. 